\title{
Application of Bat Optimization Algorithm for Economic Load Dispatch Considering Valve Point Effects
}

\author{
S. Sakthivel \\ Associate Professor, \\ Dept. of Electrical and \\ Electronics Engineering \\ V. R. S. College of Engineering \\ and Technology, Villupuram, \\ $\mathrm{TN}$, India
}

\author{
R. Natarajan \\ UG Student, \\ Dept. of Electrical and \\ Electronics Engineering \\ V. R. S. College of Engineering \\ and Technology, Villupuram, \\ $\mathrm{TN}$, India
}

\author{
P. Gurusamy \\ UG Student, \\ Dept. of Electrical and \\ Electronics Engineering \\ V. R. S. College of Engineering \\ and Technology, Villupuram, \\ TN, India
}

\begin{abstract}
Power system operation involves some kind of optimization for ensuring economy, security and stability. Economic load dispatch (ELD) is one such optimization problems and it is applied for minimizing the total fuel cost. Optimizing the fuel cost is done by properly setting the real power generation from the generators in a power system. In this work, ELD is achieved by considering two different cost functions. The bio inspired bat optimization algorithm (BOA) is used for optimally setting the values of the control variables. The BOA is a recently developed algorithm and is with less number of operators. The algorithm can be coded in any programming language easily. The proposed algorithm is tested on the standard IEEE-30 bus system and the results are compared with those of the other algorithms reported in the literature.
\end{abstract}

\section{Keywords}

Bat optimization algorithm, Economic load dispatch, Valve point effects.

\section{INTRODUCTION}

In power system operation, meeting the demand in an economical way is an important task. The statement of ELD problem is to minimize the fuel cost and this is the most common form of optimal power flow (OPF) problems [1]-[2]. Real power outputs from different generators are taken as the decision variables in this problem. Improved real power scheduling will result in considerable savings in fuel cost and hence economy of power system operation.

The primary objective of the economic dispatch problem of electric power generation is to schedule the committed generating unit outputs so as to meet the required load demand at minimum operating cost while satisfying all unit and system equality and inequality constraints [3]. This makes the ELD problem a large-scale highly non-linear constrained optimization problem. The input-output characteristics of large units are inherently highly non-linear because of valvepoint effects, generator ramp rate limits, etc. The objective of cost minimization may produce multiple local minima. The demand for an efficient optimization technique for solving this kind of highly non linear objective function is always there [4]. The results of ELD problems to be accurate, algorithms that are capable of handling the non-smoothness of the incremental cost curve are necessary.

A number of conventional optimization algorithms are exploited for solving the OPF problems [5]-[6]. The major drawback of those methods is they require smooth and convex functions for better results. Dynamic programming (DP) [7] imposes no restrictions on the nature of the cost curves and therefore it can solve ELD with inherently nonlinear and discontinuous cost curves. This method, however, suffers from the local optimality.

In the past decade, several bio inspired algorithms are attempted for ELD problems. Some of them are simulated annealing (SA) [8], evolutionary programming (EP) [9], genetic algorithms (GA) [6], tabu search (TS) algorithm [10] and particle swarm optimization (PSO) [11], which are probabilistic heuristic algorithms, have been successfully used to solve the dynamic ED problem. Theses algorithms are highly efficient and cannot easily trap in to local minima. In addition they are comfortable with all types of objective functions. Researchers across the world are constantly working to develop still efficient algorithms by copying the behaviour of nature/species. BOA is one such algorithm for optimizing engineering tasks.

In this paper, the BOA algorithm [12]-[13] is proposed for achieving improved results in the ELD problem. This algorithm is with less number of operators and hence can be easily coded in any programming language. To prove the strength of this algorithm its performance is compared with other algorithms.

\section{BAT Algorithm}

Natural bats are using the echolocation behaviour in locating their foods. This echolocation characteristic is copied in the virtual BOA algorithm with the following assumptions [12].

1. All the bats are following the echolocation mechanism and they could distinguish between prey and obstacle.

2. Each bat randomly with velocity $v_{i}$ at position $x_{i}$ with a fixed frequency $f_{\text {min }}$, varying wavelength $\lambda$ and loudness $A_{0}$ while searching for prey. They adjust the wavelength (or frequency) of their emitted pulses and adjust the rate of pulse emission $r \in[0,1]$, depending on the distance of the prey.

3. Although the loudness can vary in many ways, we assume that the loudness varies from a large (positive) $A_{0}$ to a minimum constant value $A_{\min }$.

In this algorithm either the frequency or wavelength is varied while the other parameter is kept fixed.

\subsection{Movement of Virtual Bats}

Defined rules are necessary for updating the position $X_{i}$ and velocity $V_{i}$. The new bat at the time step ' $t$ ' is found by the following equations. 


$$
\begin{aligned}
& f_{i=} f_{\text {min }}+\left(f_{\text {max }}-f_{\text {min }}\right) \beta \\
& v_{i}^{t}=v_{i}^{t-1}+\left(x_{i}^{t}-x_{*}\right) \\
& x_{i}^{t}=x_{i}^{t-1}+v_{i}^{t}
\end{aligned}
$$

Where, $\beta$ is a random number drawn between ' 0 ' and ' 1 '.

Here $x_{*}$ is the current global best location (solution)

For most of the applications, $f_{\min }=0$ and $f_{\max }=100$, depending the domain size of the problem of interest. Initially, each bat is randomly assigned a frequency which is drawn uniformly from $\left(f_{\min }, f_{\max }\right)$. For the local search part, once a solution is selected among the current best solutions,

A new solution for each bat is generated locally using random walk.

$x_{\text {new }}=x_{\text {old }}+\varepsilon A^{t}$

Where, $\varepsilon \in(1,-1)$ is a random number, while $A^{t}$ is the average loudness of all the bats at this time step. The update of the velocities and positions of bats have some similarity to the procedure in the standard particle swarm optimization as $f_{i}$ essentially controls the pace and range of the movement of the swarming particles. To a degree, BOA can be considered as a balanced combination of the standard particle swarm optimization and the intensive local search controlled by the loudness and pulse rate.

\subsection{Loudness and Pulse Emission}

Furthermore, the loudness $A_{i}$ and the rate $r_{i}$ of pulse emission have to be updated accordingly as the iterations proceed. As the loudness usually decreases once a bat has found its prey, while the rate of pulse emission increases, the loudness can be chosen as any value of convenience. Usually, $A_{0}=100$ and $A_{\min }=1$. For simplicity, we can also use $A_{0}=1$ and $A_{\min }=0$, assuming $A_{\min }=0$ means that a bat has just found the prey and temporarily stop emitting any sound. Now we have

$$
\begin{aligned}
A_{i}^{t+1} & =\alpha A_{i}^{t}+\gamma A_{i}^{t+1} \\
& =\gamma_{i}^{0}\left[\left(1-\exp \left(-\gamma_{t}\right)\right)\right]
\end{aligned}
$$

Where, $\propto$ and $\gamma$ are constants. In fact, $\propto$ is similar to the cooling factor of a cooling schedule in the simulated annealing. For any $0<\propto<1$ and $\gamma>0$ we have

$$
A_{i}^{t} \rightarrow 0, \quad \gamma_{i}^{t} \rightarrow \gamma_{i}^{0} \quad \text { as } t \rightarrow \infty
$$

In the simplicity case, we can use $\propto=\gamma$, and we have used $\propto=\gamma=0.9$ in our simulations. The choice of parameters requires some experimenting. Initially, each bat should have different values of loudness and pulse emission rate, and this can be achieved by randomization.

\section{ECONOMIC DISPATCH PROBLEM FORMULATION}

\subsection{Quadratic Cost Function}

The total cost of operation of generators includes fuel, and maintenance cost but for simplicity only variable costs need to consider are fuel costs. The fuel cost is Important for thermal power plants. The cost function is taken as a quadratic curve.

$$
\begin{aligned}
F & =\sum_{i=1}^{N} C_{i}\left(P_{G i}\right) \\
& =\sum_{i=1}^{N}\left(a_{i}+b_{i} P_{G i}+c_{i} P_{G i}^{2}\right)
\end{aligned}
$$

Where $N$ is the total number of generation units, $a_{i}, b_{i}, c_{i}$ is the cost coefficients of generating unit and $P_{G i}$ is the real power generation of $i^{\text {th }}$ unit. $i=1,2 \ldots$ to $N P$. Subject to the satisfaction of the power flow equations and the following inequality constraints on generator power, voltage magnitude and line power flow.

Subject to the following constraints:

Equality Constraints:

$P_{i}=\sum_{j=1}^{N}\left|V_{i}\right|\left|V_{j}\right|\left|Y_{j i}\right| \cos \left(\delta_{i}-\delta_{j}-\theta_{i j}\right)$

$Q_{i}=\sum_{j=1}^{N}\left|V_{i}\right|\left|V_{j}\right|\left|Y_{j i}\right| \sin \left(\delta_{i}-\delta_{j}-\theta_{i j}\right)$

$\sum P_{g i}-P_{D}-P_{L}=0$

Where $P_{D}$ is the demand power and $P_{L}$ is the total transmission network losses.

\section{Inequality Constraints}

Branch power flow limit:

$\left|S_{D i}^{\min }\right| \leq|S i| \leq\left|S_{D i}^{\max }\right| \quad i=1, \ldots n d$

Generator MVAR outputs:

$Q_{G i}^{\min } \leq Q_{G i} \leq Q_{G i}^{\min } \quad i=1, \ldots n g$

Real power generation output:

$P_{G i}^{\min } \leq P_{G i} \leq P_{G i}^{\max } \quad i=1, \ldots n g$

Transformers tap setting: 


$$
t_{k}^{\min } \leq t_{k} \leq t_{k}^{\max }
$$

\subsection{Cost Function with Sine Term}

When a generator is with multiple valve points the cost curve is not smooth. The assumption that the cost curve function is smooth becomes invalid the results are erroneous. The effect of valve points can be taken into account by adding a sine term as in equation (14).

$$
\begin{aligned}
F_{i}= & a_{i}+b_{i} P_{G i}+c_{i} P_{G i}^{2} \\
& +\left|e_{i} \times \sin \left(f_{i} \times\left(P_{G i}^{\min }-P_{G i}\right)\right)\right|
\end{aligned}
$$

Where, $F_{i}$ is the fuel cost of $i^{\text {th }}$ generator that has multistage valves in its inputs.

\section{SIMULATION RESULTS AND DISCUSSIONS}

The efficiency of the BOA based method is tested on IEEE-30 bus system. The algorithm is coded in MATLAB 7.6 environment. A Core2Duo processor based PC is used for the simulations.

The base load condition is taken for the simulation and the system bus and line data are obtained from [14]. The algorithm is run for 200 iterations with 30 bats, the frequency bounds are; $f_{\min }=-0.09$ and $f_{\max }=0.09 ; \gamma$ is the pulse emission rate uniformly distributed between ' 0 ' and ' 1 '; $v_{i}$ velocity range $(-0.05,0.8)$; range of $\beta$ is $(0,1)$, the parameter $\varepsilon$ is adjusted in the range $(-1,1)$.

\section{Case 1. Quadratic cost curve}

In this case the basic form of cost function is taken. The cost co-efficient are shown in table A-1. BOA algorithm is run for fuel cost minimization as the objective. The real power settings shown in table 1 are found to be the best one for cost minimization.

The fuel cost obtained is $802.3919 \mathrm{USD} / \mathrm{hr}$. It is lower than the cost reported in the recent literatures [15]-[16]. The loss reduction is slightly more than the loss level achieved in [16] but lower than what is given in [15].

Table 1. Optimal real power settings, fuel cost and loss (Case 1)

\begin{tabular}{|l|l|l|l|}
\hline \multirow{2}{*}{$\begin{array}{l}\text { Unit power } \\
\text { output (MW) }\end{array}$} & \multicolumn{3}{|c|}{ Method } \\
\cline { 2 - 4 } & IEP [15] & $\begin{array}{l}\text { SADE-ALM } \\
{[16]}\end{array}$ & BOA \\
\hline $\mathrm{P}_{1}$ & 176.2358 & 176.1522 & 176.27888 \\
\hline $\mathrm{P}_{2}$ & 49.0093 & 48.8391 & 49.0012 \\
\hline $\mathrm{P}_{5}$ & 21.5023 & 21.5144 & 21.3870 \\
\hline $\mathrm{P}_{8}$ & 21.8115 & 22.1299 & 22.4669 \\
\hline $\mathrm{P}_{11}$ & 12.3387 & 12.2435 & 12.2314 \\
\hline $\mathrm{P}_{13}$ & 12.0129 & 12.0000 & 11.5256 \\
\hline Total $\mathrm{P}_{\mathrm{G}}$ & 292.9105 & 292.8791 & 292.89098 \\
\hline $\mathrm{P}_{\text {loss }}$ & 9.5105 & 9.4791 & 9.49098 \\
\hline Total cost $(\$ / h)$ & 802.465 & 802.404 & 802.3919 \\
\hline
\end{tabular}

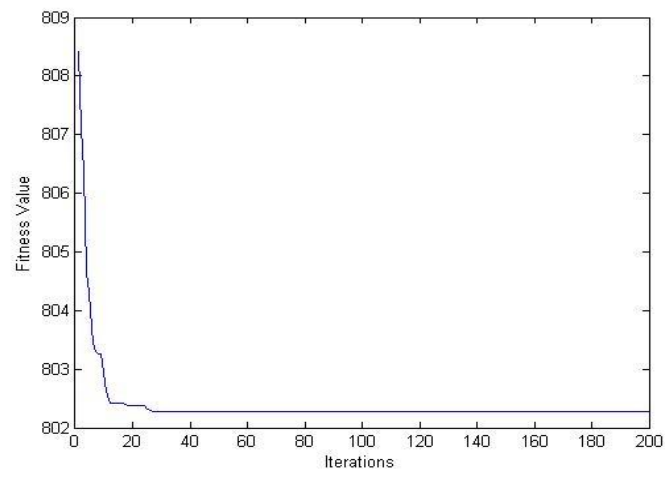

Figure 1. Convergence of BOA with quadratic cost curve

Figure 1 shows that the algorithm has converged to a better result and the algorithm stays in the optimal fuel cost.

\section{Case 2. With valve point effects}

In a steam turbine with multi stage inputs by a number of valves, the cost curve is not smooth. Fuel cost calculated using the quadratic cost curve will not be accurate as it considers the curve a smooth one. A sine function is added with the quadratic function to take into account the effect of valve points. Two more cost coefficients are introduced and thet are given in table A-2.

The total fuel cost obtained is $924.8618 \mathrm{USD} / \mathrm{hr}$. This is much lower than the fuel cost obtained by [15] and [16]. Real power loss reduction is also encouraging in this case. The optimal real power setting corresponding to minimum fuel cost is given in table 2 .

Table 2. Optimal real power settings, fuel cost and loss

(Case 2)

\begin{tabular}{|l|l|l|l|}
\hline \multirow{2}{*}{$\begin{array}{l}\text { Unit power } \\
\text { output ( } \mathrm{MW} \text { ) }\end{array}$} & \multicolumn{3}{|c|}{ Method } \\
\cline { 2 - 4 } & IEP [15] & $\begin{array}{l}\text { SADE-ALM } \\
{[16]}\end{array}$ & BOA \\
\hline $\mathrm{P}_{1}$ & 149.7331 & 193.2903 & 199.457 \\
\hline $\mathrm{P}_{2}$ & 52.0571 & 52.5735 & 19.9557 \\
\hline $\mathrm{P}_{5}$ & 23.2008 & 17.5438 & 22.7162 \\
\hline $\mathrm{P}_{8}$ & 33.4150 & 10.0000 & 19.3118 \\
\hline $\mathrm{P}_{11}$ & 16.5523 & 10.0000 & 16.5307 \\
\hline $\mathrm{P}_{13}$ & 16.0875 & 12.0000 & 16.2981 \\
\hline Total $\mathrm{P}_{\mathrm{G}}$ & 291.0458 & 295.4096 & 294.269 \\
\hline $\mathrm{P}_{\text {loss }}$ & 7.6458 & 12.0096 & 10.869 \\
\hline Total cost $(\$ / \mathrm{h})$ & 953.573 & 944.031 & 924.8618 \\
\hline
\end{tabular}




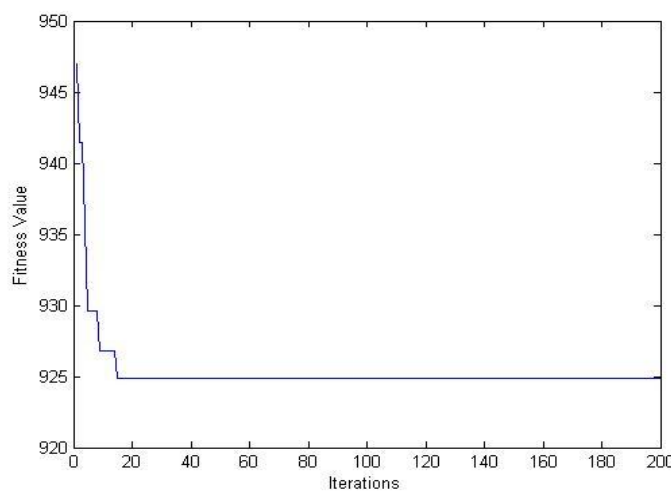

Figure 2. Convergence of BOA with valve effects

The excellent convergence characteristic of BOA in ELD problem with valve point effects is depicted in figure 2 . It is clear from the diagram that the algorithm takes only 20 iterations and hence takes less time for convergence.

\section{CONCLUSIONS}

In this work, a new bio inspired algorithm is implemented for the ELD problem. The numerical results clearly show that the proposed algorithm gives better results. The BOA optimization algorithm outperforms the recently reported algorithms. The strength of the algorithm is proved with two different objective functions, both smooth and non smooth functions.

The algorithm is with less number of operators and easy to be calculated in any computer language. Power system operation optimization problems can be attacked with this algorithm. Power system operators can use this algorithm for various optimization tasks.

\section{APPENDIX}

Table A.1 : Generator cost coefficients in case 1

\begin{tabular}{|l|l|l|l|l|l|}
\hline \multirow{2}{*}{$\begin{array}{l}\text { BUS } \\
\text { NO. }\end{array}$} & \multicolumn{2}{l}{$\begin{array}{l}\text { Real Power Output } \\
\text { Limit(MW)S }\end{array}$} & \multicolumn{2}{l|}{ Cost Coefficients } \\
\cline { 2 - 6 } & Min & Max & a & b & c \\
\hline 1 & 50 & 200 & 0.00375 & 2.00 & 0 \\
\hline 2 & 20 & 80 & 0.01750 & 1.75 & 0 \\
\hline 5 & 15 & 50 & 0.06250 & 1.00 & 0 \\
\hline 8 & 10 & 35 & 0.00834 & 3.25 & 0 \\
\hline 11 & 10 & 30 & 0.02500 & 3.00 & 0 \\
\hline 13 & 12 & 40 & 0.02500 & 3.00 & 0 \\
\hline
\end{tabular}

Table A-2 : Generator cost coefficients in case 2

\begin{tabular}{|l|l|l|l|l|l|l|l|}
\hline $\begin{array}{l}\text { Bus } \\
\text { No. }\end{array}$ & \multicolumn{2}{|l|}{$\begin{array}{l}\text { Real Power } \\
\text { limit }\end{array}$} & \multicolumn{5}{|c|}{ Cost Coefficients } \\
\cline { 2 - 8 } & Min & Max & a & b & c & e & f \\
\hline 1 & 50 & 200 & 0.00160 & 2.00 & 150 & 50 & 0.063 \\
\hline 2 & 20 & 80 & 0.01000 & 2.50 & 25 & 40 & 0.098 \\
\hline
\end{tabular}

\section{REFERENCES}

[1] Abou El Ela A. A., Abido M.A., Spea S.R., "Optimal Power Flow using Differential Evolution Algorithm",
Electric Power System Research, Vol. 80, No. 7, pp. 878-885, July 2010.

[2] Sayah S, Zehar K, "Modified Differential Evolution Algorithm for Optimal Power Flow with Non-smooth Cost Functions", Energy Conversion and management, Vol. 49, No. 11, pp. 3036-3042, November 2008.

[3] N. Sinha, R. Chakrabarti, P. K. Chattopadhyay, "Evolutionary Programming Techniques for Economic Load Dispatch", IEEE Transactions on Evolutionary Computations, Vol. 7, No. 1, pp. 83-94, 2003.

[4] He Da-kuo, Wang Fu-li, Mao Zhi-zhong, "Hybrid Genetic Algorithm for Economic Dispatch with Valvepoint Effect", Elsevier, Electric Power Systems Research, 78, pp. 626-633, 2008.

[5] Yan X, Quantana VH, "Improving an Interior Point based OPF by Dynamic Adjustments of Step Sizes and Tolerances", IEEE Transactions on Power Systems, Vol. 14, No. 2, pp.709-717, May 1999.

[6] Habiabollahzadeh H, "Hydrothermal Optimal Power Flow based on Combined Linear and Nonlinear Programming Methodology", IEEE Transactions on Power Systems, Vol. 4, No. 2, pp. 530-537, May 1989.

[7] Z.-X. Liang, J.D. Glover, "A Zoom Feature for a Dynamic Programming Solution to Economic Dispatch Including Transmission Losses", IEEE Transactions on Power Systems, Vol.7, No. 5, pp. 544-549, 1992.

[8] KP. Wang, CC. Fung, Simulate Annealing based Economic Dispatch Algorithm, IEE Proc C 1993, Vol. 140, No. 6, pp. 507-513.

[9] HT. Yang, PC. Yang, CL. Huang. , "Evolution Programming based Economic Dispatch for Units with Non-smooth Fuel Cost Functions", IEEE Transactions on Power Systems, 1996, Vol. 11, No.1, pp. 112$118,1996$.

[10] W. Ongsakul, Dechanupapritttha S, Ngamroo I, Tabu Search Algorithm for Constrained Economic Dispatch, In: Proceedings of the international conference on power systems, Wuhan, China, September 2001, pp.428-433.

[11] Gaing Zwe-Lee, "Particle Swarm Optimization to Solving the Economic Dispatch Considering the Generator Constraints", IEEE Transactions Power Systems, Vol. 18, No. 3, pp. 1187-1195, 2003.

[12] Yang, X. S., "Bat Algorithm for Multi-objective Optimization”, Int. J. Bio-Inspired Computation, Vol. 3, No. 5, pp.267-274, 2011.

[13] Bora, Teodoro C, "Bat-Inspired Optimization Approach for the Brushless DC Wheel Motor Problem", IEEE Transactions on Magnetics, Vol.48, No. 2, pp. 947-950, Feb. 2012.

[14] Power Systems Test Case, 2000, The University of Washington http://www.ee.washington.edu/research/pstca. 
[15] Y. Labbi, D. Ben Attous, "Big Bang-Big Crunch Optimization Algorithm for Economic Dispatch with Valve-Point Effect", Journal of Theoretical and Applied Information Technology, Vol. 16, No.1, pp. 48-56, 2010.

[16] Thitithamrongchai, B. Eua-arporn, "Self-adaptive Differential Evolution Based Optimal Power Flow for Units with Non-smooth Fuel Cost Functions", JES Journal of Electrical Systems, Vol. 3, No. 2, pp. 88-99, 2007.

\section{AUTHOR'S PROFILE}

S. Sakthivel received the Degree in Electrical and Electronics Engineering in 1999 from Madras University and Master Degree in Power Systems Engineering in 2002 from Annamalai University. He is pursuing the Ph.D., Degree in
Electrical Engineering faculty from Anna University of Technology, Coimbatore, India. He is presently working as an Associate Professor in Electrical and Electronics Engineering at V.R.S. College of Engineering and Technology, Villupuram, Tamil Nadu, India. His research areas of interest are Power System control, Optimization techniques, FACTS, Economic load dispatch, Power system deregulation and Voltage stability improvement.

R.Natarajan is an undergraduate student with the Department of Electrical and Electronics Engineering at VRS College of Engineering and Technology, Villupuram, Tamil Nadu, India. $\mathrm{He}$ is interested in the area of economic load dispatch.

P.Gurusamy is an undergraduate student in the Department of Electrical and Electronics Engineering at VRS College of Engineering and Technology, Villupuram, Tamil Nadu, India. $\mathrm{He}$ is interested in power system operation optimization by using intelligent techniques 